\title{
Ten-year pathological study of Beall mitral valve prostheses
}

\author{
KS CHANG, J FERNANDEZ, SD CHA, SS YANG
}

From the Departments of Pathology, Thoracic Surgery, and Cardiology, Deborah Heart and Lung Center, Browns Mills, New Jersey, USA

ABSTRACT Detailed pathological studies are reported on 20 cloth-covered Beall mitral valve prostheses, which had to be removed for valve failure nine months to 10 years after implantation. Results in all patients except one indicated that there was a progressive and persistent granulomatous reaction that continued up to at least 10 years. Although the rate of tissue ingrowth into the valve decreased with time, the total volume of tissue formation increased. Cloth wear and disruption and deformity of the teflon discs was frequently seen. In these 20 valves the desired result-namely, the complete and smooth endothelialisation of the prosthesis-was certainly not achieved.

In an effort to reduce the incidence of one of the main complications of prosthetic valves, porous knitted Dacron cloth was used to enclose completely the frame of the Beall valve prosthesis. This achieved, to a great extent, the goal of tissue ingrowth and reduced thrombo-embolic complications. Although there have been short-term studies of the granulation tissue ingrowth on such prosthesis, the pathological features of the host response to Dacron fabric over a 10-year implantation period have not been well described. This communication presents the results of pathological studies of 20 Beall prostheses which were removed and examined up to 10 years after implantation.

\section{Methods}

Seventeen 103 model Beall valves, two model 104, and one model 105 valves were removed surgically from the mitral position between 1974 and 1977 and subjected to study after fixation in McDowell fixative $(10 \%$ neutral buffered formalin with $2 \%$ glutaraldehyde). Valve prostheses with secondary inflammation from bacterial endocarditis were excluded from the study.

\section{GROSS EXAMINATION}

Each valve was examined thoroughly for (a) valve function-that is, opening and closing, (b) tissue growth, and (c) wear of cloth and/or disc and cloth

Address for reprint requests: Dr KS Chang, Department of Pathology, Deborah Heart and Lung Center, Browns Mills, New Jersey 08015, USA. disruption. Each specimen was then photographed and each $35 \mathrm{~mm}$ Kodachrome slide projected at 10 times magnification. The size and shape of the inflow opening was exactly copied on semi-transparent paper and the exact area in square centimeters of the inflow opening was measured by planimetry.

MORPHOMETRICAL ANALYSIS

Each cloth cover was then removed from the valve frame and the exact volume of the cloth and tissue was measured by water displacement. Secondly, the cloth cover was stretched on a cork board and the granulation tissue was quantitated by a "point counting" technique. ${ }^{1}$ Finally, the entire cloth cover was serially sectioned every 30 degrees, yielding 12 pieces. The area of a lateral surface of each piece was again measured by point counting. The volume of granulation tissue was determined by the following formula:

Granulation tissue $(\mathrm{ml})=$ cloth cover $(\mathrm{ml}) \times$ score of granulation tissue counting score of cloth cover counting

HISTOLOGICAL PREPARATION

Each of the 12 pieces of the sectioned cloth were stained with Haematoxylin and eosin (H and E), Masson's Trichrome, PAS, Alcian Blue (ph 2.5), Gomori's Aldehyde, Fuchsin Elastic, Gomori's Reticulum, and Mallory's Collagen. Each slide was examined under the microscope to determine the extent of the endocardial cell growth, the degree of the foreign body reaction, and the extent of the collagen layer formation. 


\section{Results}

There were seven men and 13 women, aged 23-68 years (table). The most common clinical features at the time of surgery were shortness of breath, haemolytic anaemia, and congestive heart failure. The duration of prosthetic valve implantation ranged from nine months to 10 years.

Gross examination of the prosthetic valves revealed abundant collagen tissue on both the

Table Clinical summary of 20 patients with Beall prosthesis

\begin{tabular}{llllll}
\hline Patient & $\begin{array}{c}\text { Age } \\
(y \boldsymbol{r})\end{array}$ & Sex & $\begin{array}{l}\text { Beall } \\
\text { model no }\end{array}$ & $\begin{array}{c}\text { Duration } \\
(y \boldsymbol{r})\end{array}$ & Symptoms \\
\hline 1 & 44 & M & 104 & $9 / 12$ & SOB, LHF \\
2 & 47 & M & 104 & $15 / 12$ & SOB, Haemolysis \\
3 & 53 & F & 105 & $24 / 12$ & SOB, CHF \\
4 & 52 & M & 103 & $42 / 12$ & SOB, chest pain \\
5 & 39 & M & 103 & $43 / 12$ & Haemoptysis, fainting \\
6 & 55 & F & 103 & $43 / 12$ & Haemolysis, lung oedema \\
7 & 60 & F & 103 & $43 / 12$ & SOB, haemolysis \\
8 & 55 & F & 103 & $49 / 12$ & SOB, palpitations \\
9 & 43 & M & 103 & $56 / 12$ & SOB \\
10 & 56 & F & 103 & $59 / 12$ & SOB \\
11 & 48 & F & 103 & $511 / 12$ & SOB, palpitations \\
12 & 43 & F & 103 & $6-$ & SOB, palpitations \\
13 & 45 & F & 103 & $6-1$ & SOB, weakness \\
14 & 23 & M & 103 & $63 / 12$ & Haemolysis \\
15 & 66 & F & 103 & $67 / 12$ & SOB, haemolysis \\
16 & 44 & F & 103 & $610 / 12$ & Haemolysis, lung oedema \\
17 & 58 & F & 103 & $79 / 12$ & CHF \\
18 & 54 & F & 103 & $81 / 12$ & SOB, haemolysis \\
19 & 56 & M & 103 & $811 / 12$ & SOB \\
20 & 68 & F & 103 & $10-$ & SOB, haemolysis \\
& & & & &
\end{tabular}

SOB $=$ shortness of breath;

$\mathrm{CHF}=$ congestive heart failure

LHF = left heart failure. ventricular and atrial surfaces, but little in the inflow area. Sixteen out of 18 Teflon discs displayed varying degrees of notching and indentations caused by등 wear on the struts, ${ }^{2}$ one disc was pyrolite, and in one model 103 prosthesis implanted for six years, the disc. was missing. This patient recovered from an emergency operation.

A common and important defect which caused $a \vec{\circ}$ variable degree of obstruction at the inflow opening of the valve was dehiscence of the cloth cover at thew inferior margin of the inflow area, where the disc hit the cloth repetitively over the metal seat. The cloth had worn thin in some valves around the rim and finally ruptured all round so that the cloth edgei was then free to turn up into the orifice. The degreew of obstruction of the inflow lumen by dehiscence of the Dacron cloth cover varied from $2 \%$ to $55 \%$ (fig 1). The amount of obstruction did not correlate $\overrightarrow{-}$ with the duration of implantation. Forty-five per cento of the cases showed severe inflow obstruction $(23 \%$ to $55 \%)$ in a four to 10 year postoperative period.

Quantitative measurement of granulation and $\overrightarrow{0}$ collagen formation showed that the rate of new? tissue formation per month gradually declined after the prosthesis had been in place for two years (fig 2) Tissue ingrowth occurred at a rate of $0.12 \mathrm{ml}$ per month at nine months after implantation and gradually decreased to $0.02 \mathrm{ml}$ per month at 10 years after implantation. The total volume of tissue formation, however, increased with time, up to a의 volume equivalent to $77 \%$ of the entire cloth cover at 10 years after implantation (fig 3). Thus, the speed of

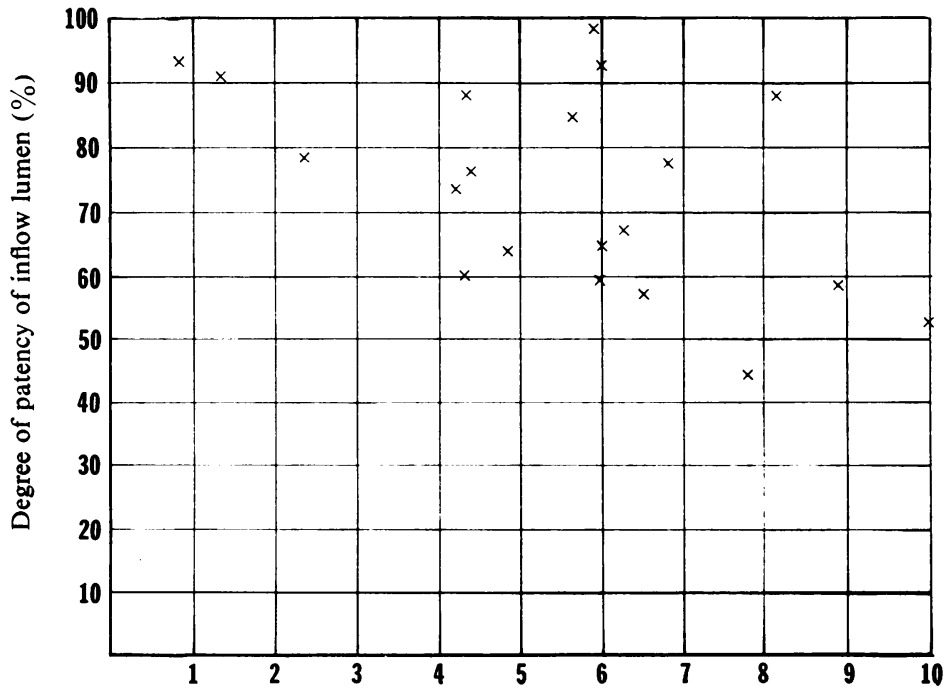

Duration of prosthetic valve implants $(\mathrm{yr})$
Fig 1 Degree of patency of the central을 valve lumen up to 10 years after operation. 


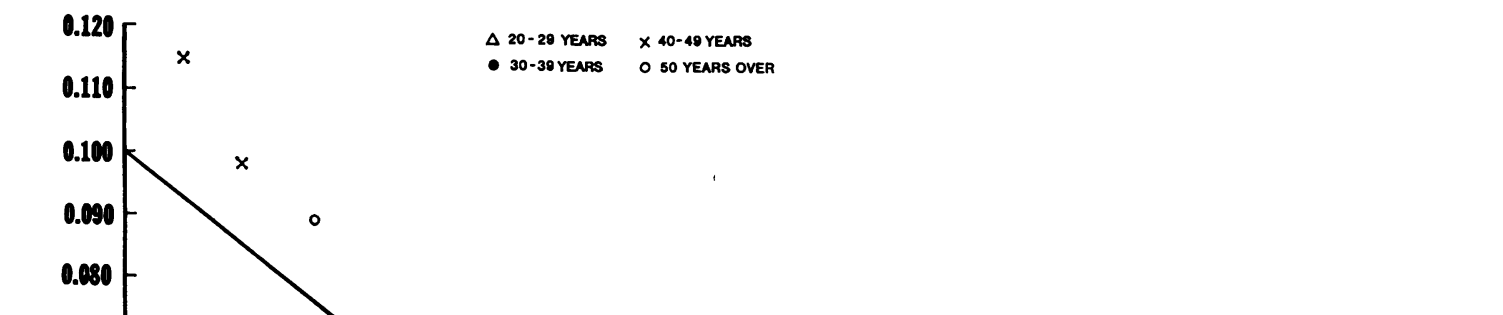

Fig 2 Rate of granulation tissue growth per month and during a 10-year postoperative period on 20 Beall prostheses.

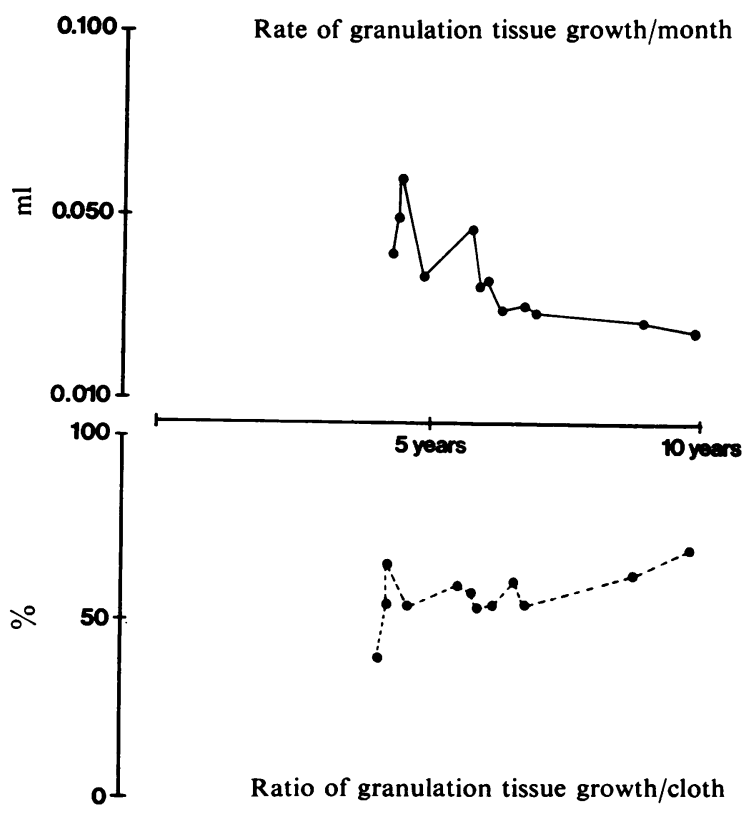

growth and intensity of the granulation process gradually declines although the total amount of granulation tissue increases. The foreign body granulomatous inflammation in and on Dacron cloth is a chronic, longstanding process. It is preceded by a stage of exudation (fig 4), progresses to a stage of granuloma (fig 5), and finally to a stage of healing (fig 6). This process is extremely slow. Also, the formation of the collagen layer on Dacron cloth cover is in many cases irregular and "lumpy". It occurs on the atrial and ventricular surface of the valve prosthesis. The inflow area surprisingly shows only minimal granulation tissue growth even after 10

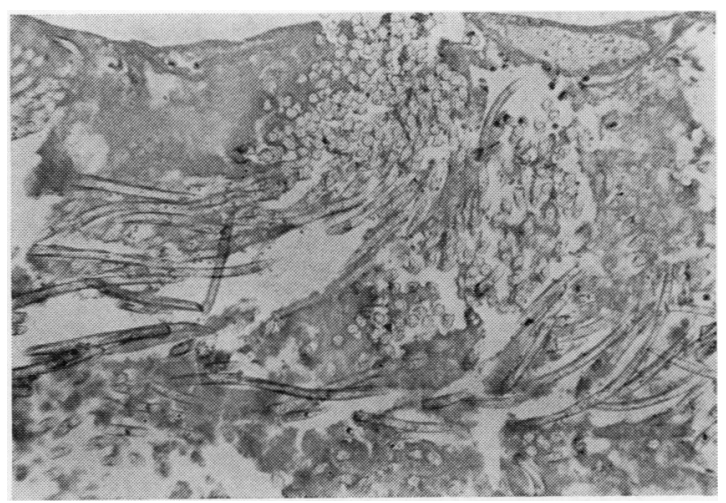

Fig 3 Rate of granulation tissue growth per month and ratio of granulation tissue growth to cloth cover on 12 Beall prostheses model 103, medium size.

Fig 4 Stage of exudation in fibrin mesh at the edge of granulation tissue at the inflow area nine months after implantation. ( $H$ and $E \times 200$ ) 


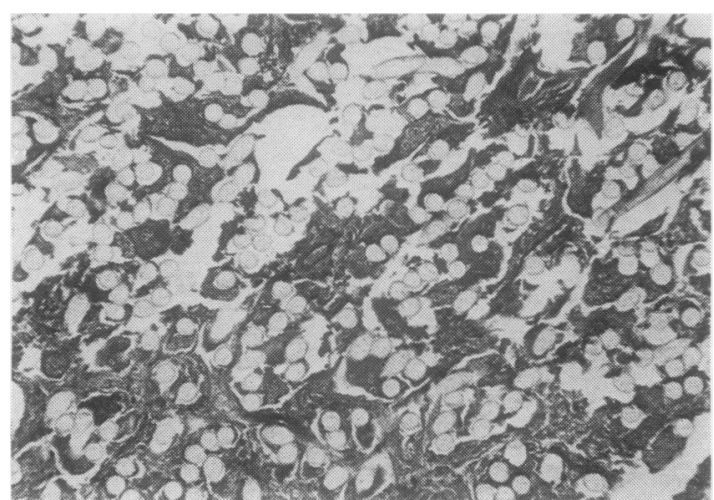

Fig 5 Stage of chronic granulomatous inflammation, six years after implantation. ( $H$ and $E \times 200$ )

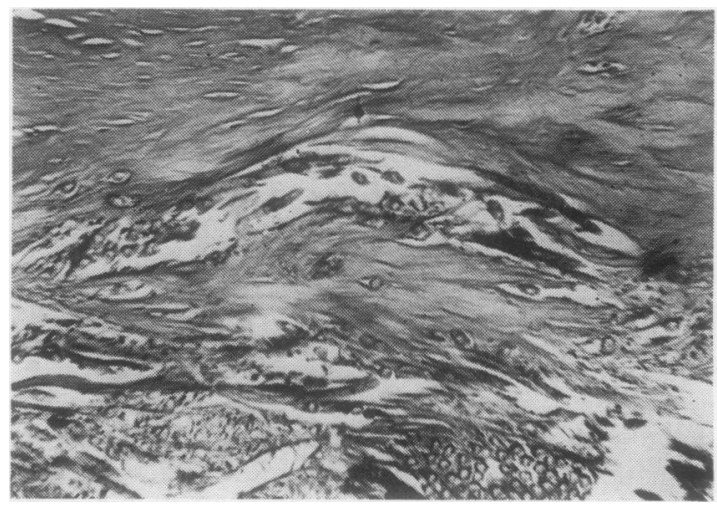

Fig 6 Stage of healing with dense collagenisation, 10 years after implantation. ( $H$ and $E \times 200$ ) years. One prosthesis implanted for only nine months showed ideal granulation tissue formation with a $\overline{0}$ thin enclosure of the whole Dacron cloth cover up to $\frac{\mathrm{\sigma}}{\mathrm{\sigma}}$ the inflow area (fig 7). An intriguing finding was the discovery that one model 103 Beall prosthesis $\overparen{\nabla}$ implanted for six years in a 43-year-old women did not show any foreign body granulomatous reaction $\omega$ in and around the cloth cover at all, yet the atrial $\overrightarrow{0}$ aspect of the prosthesis was covered with an appreci- $\overrightarrow{\vec{\omega}}$ able amount of amorphous collagen tissue.

\section{Discussion}

Dacron cloth is a polymeric, porous, knitted fabric $\stackrel{i}{*}$ which has been widely used in various prostheses, $\vec{v}$ including arterial grafts and cardiac valve pros- 0 theses. $^{34}$ Its application to cardiac valve prostheses greatly reduced thrombo-embolic complications. ${ }^{56} \vec{T}$ Our experience with Dacron-Velour cloth-covered $\frac{1}{\circ}$ Beall valve prostheses in over 500 single mitral valve replacements showed a significant decrease in thromboembolic complications compared to our $\vec{\theta}$ previous experience using uncovered prostheses. ${ }^{78}$ The fundamental mechanism underlying this improvement in thromboembolic complications is the ingrowth of granulation tissue in the Dacron Velour cloth cover.

Our studies of implanted Beall prostheses indicate that the foreign body granulomatous tissue reaction $\stackrel{\mathbb{Q}}{2}$ to Dacron cloth fabric is a chronic longstanding $\overrightarrow{\vec{O}}$ process. It is intense shortly after implantation and 3 then gradually declines, yet it still persists for up to $\overrightarrow{ }$ 10 years. Apparently, Dacron fibres are an insoluble material which gradually release a stimulant and steadily incite a foreign body tissue reaction. Healing by collagenization is painstakingly slow. The rate at

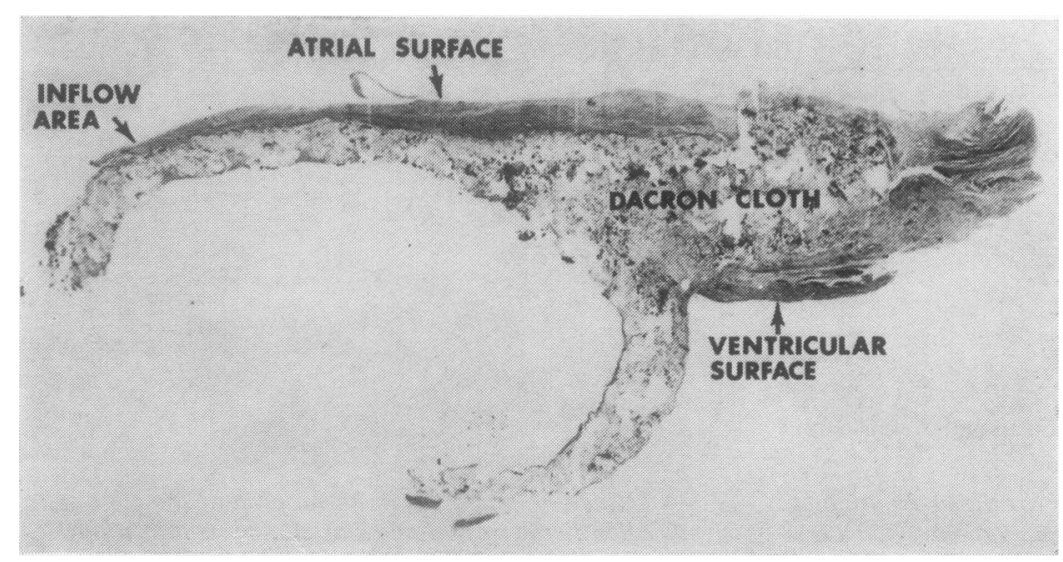

Fig 7 Ideal granulation tissue enclosure of entire cloth cover, after implantation for only nine months. 
which granulomatous inflammation evolves depends on the inciting agent and the state of the host. ${ }^{9}$

Macrophage infiltration with formation of a foreign body granuloma is the characteristic cellular response to Dacron. ${ }^{10}$ With a prosthetic valve implant, this tissue reaction is intensified by mechanical trauma and surgical suturing. The time interval for this foreign body response is variable. Dacron fibres seem relatively inert as inciting substances and induce low "turn-over" granulomas. Once established, however, these granulomas maintain themselves by a combination of exudation and proliferation, and may persist for as long as the inciting agent exists.

The function of the granuloma is to eliminate unwanted substances from the host. The principal elements are mononuclear phagocytes. ${ }^{12}$ Foreign substances may evoke a granulomatous response in three stages-monocytic infiltrate, aggregation into a mature granuloma and into an epithelioid one. The ability of a foreign substance to evoke a granulomatous inflammation may correlate with its content of substances capale of inducing maturation of macrophages. Products of streptococcal cell walls, for instance, evoke modest maturation of macrophages in vitro and a mature granuloma in vivo. ${ }^{13}$ The colloidal form of carragenan evokes both, while the calcium form can evoke neither. ${ }^{14}$ However, the ability to stimulate maturation of the macrophage cannot alone evoke a granuloma. Endotoxin stimulates macrophages in culture but does not evoke granulomas. One additional property needed for the development of granulomas is the persistence of a revoking agent, such as those which are resistant to degradation by macrophages. ${ }^{15}$ In the last stages, fibroblasts proliferate and penetrate into granulomas and lay down collagen fibres in an interlacing network. Usually, the surface of the Dacron cloth is covered with layers of fibroblasts and collagen fibers with formation of a so-called "pseudointima". Our observations indicate that there is no evidence of true endothelial cell growth on the surface of the collagen layers although many authors claim that endothelialisation takes place over the entire surface of the granulation tissue.

It has been shown that the degree of the fibrous tissue ingrowth over Dacron cloth is dependent on the size of the knitting pore. ${ }^{11}$ If the size is so small as to prevent cellular invasion, then there will be excessive granulation tissue growth, as seen on earlier models of the Starr-Edwards valve prosthesis. It has been stated that the use of polymeric substance with a pore size of less than $0.4 \mu$ should be avoided in any prosthetic device, because of this excessive fibroblastic tissue proliferation.

One of the most intriguing observations is that there was little evidence of granulomatous host response to the Dacron cloth in one prosthesis implanted for six years. It is possible that this response could be the result of complete healing with no residual inflammatory process. The covering layer of fibrous tissue appeared totally amorphous and there was no clue as to the nature of the preceding inflammatory process, whether it was granulomatous or simple chronic inflammation.

Because of the tendency of the collagen tissue ingrowth over the Dacron cloth of implanted valve prostheses to be uneven in most cases, the original goal of encapsulation of the entire Dacron cloth cover does not appear to have been fulfilled. Furthermore, our study disclosed that wear of the Dacron cloth was an extremely common phenomenon, causing obstruction of the inflow lumen, haemolytic anaemia, and in some cases circulatory failure.

\section{References}

${ }^{1}$ Weibel ER. Morphometry of the human lung. New York: Academic Press, 1963.

${ }^{2}$ Silver MD, Wilson GJ. Pathology of wear in the Beall model 104 heart valve prosthesis. Circulation 1977;56: 617-22.

${ }^{3}$ Szilagyi DE, Smith RF, Elliott JP, Allen HM. Longterm behavior of a Dacron arterial substitute: clinical roentgenologic and histologic correlations. Ann Surg $1952 ; 162: 453-77$.

+ Suavage L.R, Berger K, Wood SJ, Sameh AA et al. A very thin, porous knitted arterial prosthesis: experimental data and early clinical assessment. Surgery 1969;65:7888.

${ }^{5}$ Davila JC, Amongero F. Sethi RS, Rincon NL et al. The prevention of thrombosis in artificial cardiac valves. Ann Thorac Surg 1966;2:714-41.

${ }^{6}$ Braunwald NS, Morrow AG. Tissue ingrowth and the the rigid heart valve: review of clinical and experimental experience during the past year. Thorac Cardiovasc Surg 1968;56:307-22.

${ }^{7}$ Nichols HT, Fernandez J, Morse D et al. Improved results in 336 patients with isolated mitral Beall valve replacement. Chest $1972 ; 62: 266-72$.

${ }^{8}$ Fernandez J, Morse D, Spagna P et al. Results of mitral valve replacement with Beall prostheses in 209 patients. $J$ Thorac Cardiovasc Surg 1976;71:218-25.

${ }^{9}$ Adams DO. The granulomatous inflammatory response. Am J Pathol 1967;84:164-91.

${ }^{10}$ Goldner RD, Adams DO. The structure of mononuclear phagocytes differentiating in vivo. III The effect of particulate foreign substances. Am J Pathol 1977;89:33550 .

${ }^{11}$ O'Connell TX, Fee HJ, Golding A. Sarcoma associated with Dacron prosthetic material: case report and review of literature. J Thorac Cardiovasc Surg 1976;72:94-6.

12 Spector WC. The macrophage: its origins and role in pathology. Pathobiol Annu 1974;4:33-64.

${ }^{13}$ Davies P, Allison AC. Secretion of macrophage enzyme: relation to pathogenesis of chronic inflammation. In: Nelson DS, ed. Immunobiology of macrophages. New York: Academic Press, 1975:428-61.

14 Page RC, Davies P, Allison AC. Participation of mononuclear phagocytes in chronic inflammatory diseases. $J$ Reticuloendothelial Soc 1974;15:413-38.

${ }^{15}$ Spector WC. The granulomatous inflammatory exudate. Int Rev Exp Pathol 1969;8:1-55. 